\title{
A prospective study on prescribing pattern of drugs in geriatric patients in the department of medicine in a tertiary care center
}

\author{
Priya Mohan B. N. ${ }^{*}$, Suma Jayaram²
}

${ }^{1}$ Department of Pharmacology, Al Azhar Medical College and Super Specialty Hospital, Thodupuzha, Kerala, India

${ }^{2}$ Department of Pharmacology, St. John's Medical College and Super Specialty Hospital, Bangalore, Karnataka, India

Received: 02 February 2021

Accepted: 18 February 2021

\section{*Correspondence:}

Dr. Priya Mohan B. N.,

Email: priyamohan.n@gmail.com

Copyright: (C) the author(s), publisher and licensee Medip Academy. This is an open-access article distributed under the terms of the Creative Commons Attribution Non-Commercial License, which permits unrestricted non-commercial use, distribution, and reproduction in any medium, provided the original work is properly cited.

\begin{abstract}
Background: India stands at $3^{\text {rd }}$ position with large elderly population in the world. Elderly population has special problems related to health, social support, and economic security. Comorbidities in elderly people are frequent, which require use of multiple medications which increases the number of inappropriate medications noncompliance, economic burden, adverse drug reactions (ADRs), and drug interactions. The overall incidence of ADR is two to three times higher due to physiological and pharmacological variations. Currently used screening tools for inappropriate prescription in old age are: Beers criteria and inappropriate prescribing in the elderly tool (IPET).

Methods: A prospective observational study of elderly patients of either sex admitted in the medicine ward, conducted from May 2019-November 2019. A total of 102 prescriptions were collected and analysed. Data was analysed using Microsoft excel.

Results: In this study most of the patients (67 out of 102) were in the age group 65-70 years with male population (73\%) dominance. Most of the patient were admitted due to cardiovascular (35.84\%) and respiratory system (14.15\%) disorder. Anti-diabetics (17.64\%) followed by anti-microbials (14.24\%) were the most commonly prescribed medicines in this study. Our study revealed poly pharmacy in geriatric patients with an average number of drugs per prescription being 6.07. According to BEER's criteria $3.47 \%$ of total drugs prescribed were inappropriate

Conclusions: In this study most of the patients had co morbid conditions, cardiovascular disease and diabetes being the common cause led to polypharmacy. A high number of potential prescription errors were found.
\end{abstract}

Keywords: Elderly, Beer's criteria, Inappropriate prescribing in the elderly tool, Polypharmacy

\section{INTRODUCTION}

The elderly population is increasing rapidly worldwide. Their growth rate $(1.9 \%)$ is higher than general population $(1.2 \%)^{1}$

At present, India is the third country after China and USA with large elderly population in the world. Elderly population has special problems related to health, social support, and economic security. Their healthcare need differs from younger people.
Though elderly is reported to be responsible for half the total drug usage, less than $5 \%$ of randomized control trials have been designed for them. ${ }^{2}$ Therefore, data available from younger subjects are used to guide prescribing in elderly.

Physiological and pharmacological variations in elderly population include decreased total body mass, blood flow to various organs, immunity, and nervous functions; down-or upregulation of various receptors; and disturbance in first pass metabolism, bioavailability, metabolism, and excretion. ${ }^{3,4}$ 
Presence of comorbidities in elderly people require use of multiple medications which increase the irrational prescription, use of inappropriate medications, noncompliance, economic burden, adverse drug reactions (ADRs), and drug interactions. ${ }^{5}$ The overall incidence of ADR is two to three times higher and most of them are potentially avoidable in elderly patients. ${ }^{6}$

At present, there are only two well-described and validated screening tools for IP in old age in literature aimed at regular clinical use: Beers criteria and IPET. Beers' criteria dominate the international literature since they were first described in 1991. Originally, Beers criteria were in essence, a list of 30 drugs to be avoided in the elderly population, regardless of diagnosis. Beers criteria have been subsequently modified to facilitate use in community-dwelling elderly and have been recently updated by, The American geriatrics society in 2012. ${ }^{7}$

The present study was conducted to analyses prescription pattern and inappropriate drug usage in elderly patients by Beer's criteria.

\section{METHODS}

\section{Source of data}

Elderly patients visiting medicine outpatient unit in $\mathrm{Al}$ Azhar medical college and super specialty hospital were analyzed.

\section{Study criteria}

Elderly patients were enrolled by taking their consent into the study by considering following criteria:

\section{Inclusion criteria}

Elderly patients visiting OPD of medicine, patients of above 65 years and of either sex and patients who were willing to participate in the study were included in the study.

\section{Exclusion criteria}

Patients of below 65-year age and who were not willing to participate in the study were excluded from the study.

\section{Methods of collection of data}

Study site: Study was conducted in outpatient department of medicine at Al Azhar medical college and super specialty hospital.

Study duration: Study was carried out for a period of 6 months (May 2019-November 2019).

Study design: Descriptive study.

\section{Procedure}

Study was conducted at the outpatient department of medicine. The elderly patients visiting to hospital were enrolled in the study considering the inclusion and exclusion criteria. Informed consent was taken from each patient at the time of enrollment in to the study. Details regarding demography, disease and treatment was collected from the OPD cards of the patient in a specially designed patient data collection form and potentially inappropriate medication was noted as per Beers criteria.

\section{Statistical analysis}

Results were expressed as mean, standard deviation and percentages.

\section{RESULTS}

Figure 1 and 2 shows that most of the patients (67 out of 102) were in the age group 65-70 years with male population $(73 \%)$ dominance.

Figure 3 shows that majority of the patient were admitted due to cardiovascular $(35.84 \%)$ and respiratory system $(14.15 \%)$ disorder.

Anti-diabetics (17.64\%) followed by antimicrobials (14.24\%) were the most commonly prescribed medicines in this study. Whereas ranitidine, aspirin, and diclofenac were reported as commonly utilized drugs (Figure 4). Average number of drugs per prescription was 6.07 (Figure 5).

Table 1 showing potentially inappropriate drugs prescribed based on Beer's criteria.

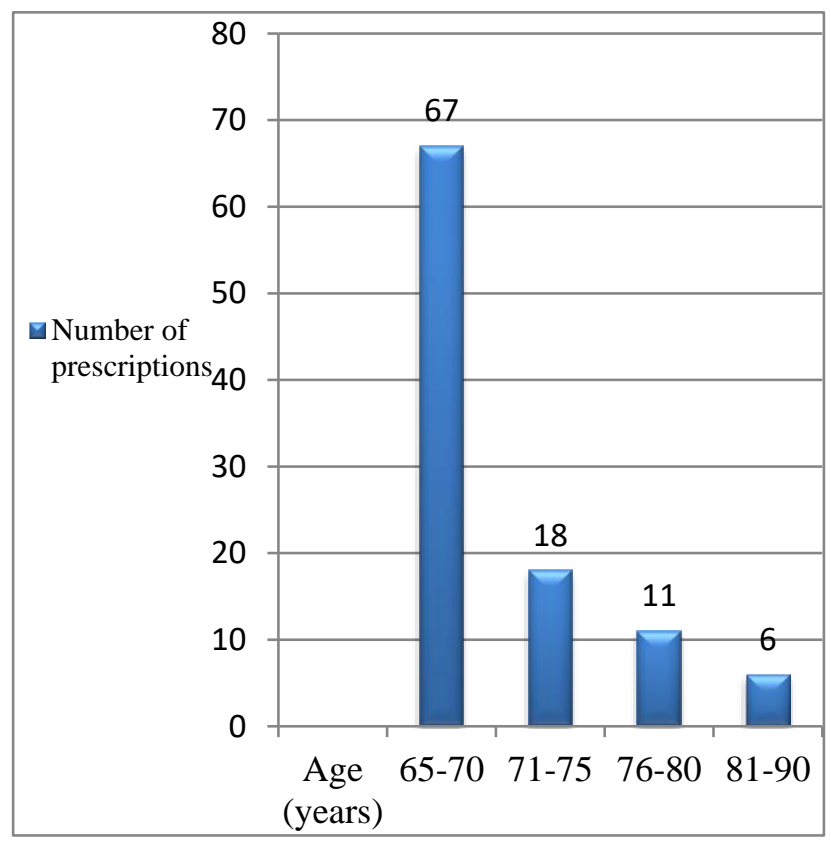

Figure 1: Age distribution of geriatric patients. 


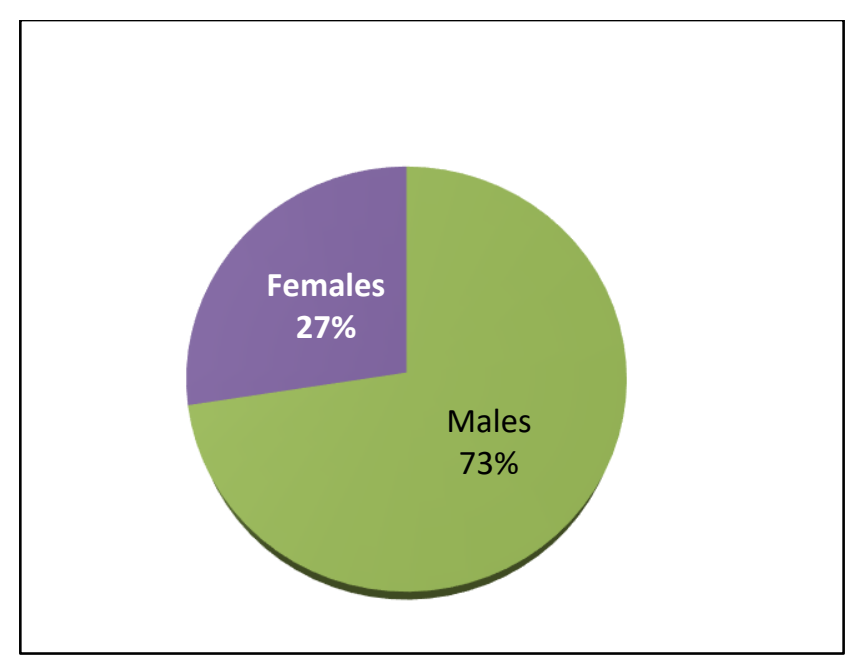

Figure 2: Gender distribution of geriatric patients.

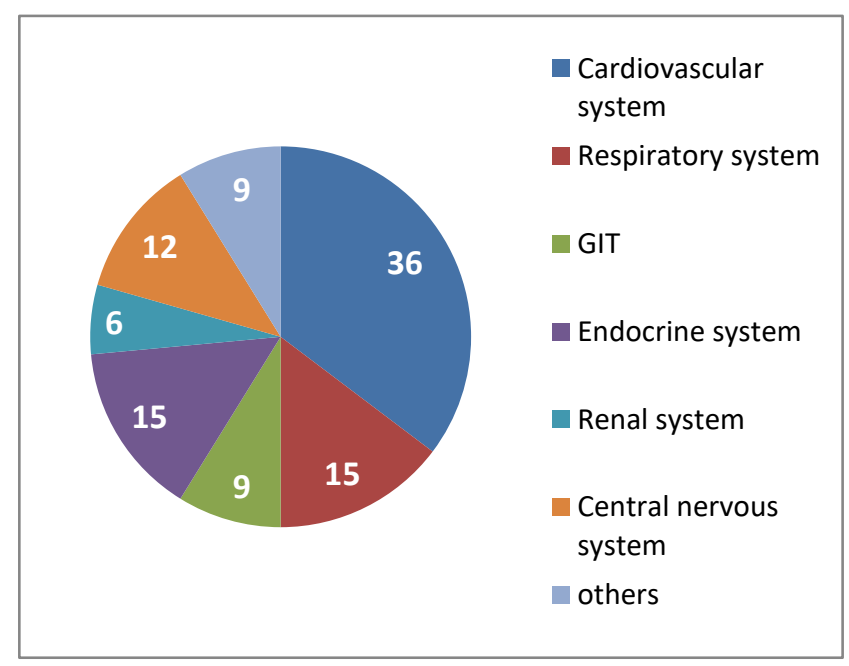

Figure 3: Distribution of patients by system affected.

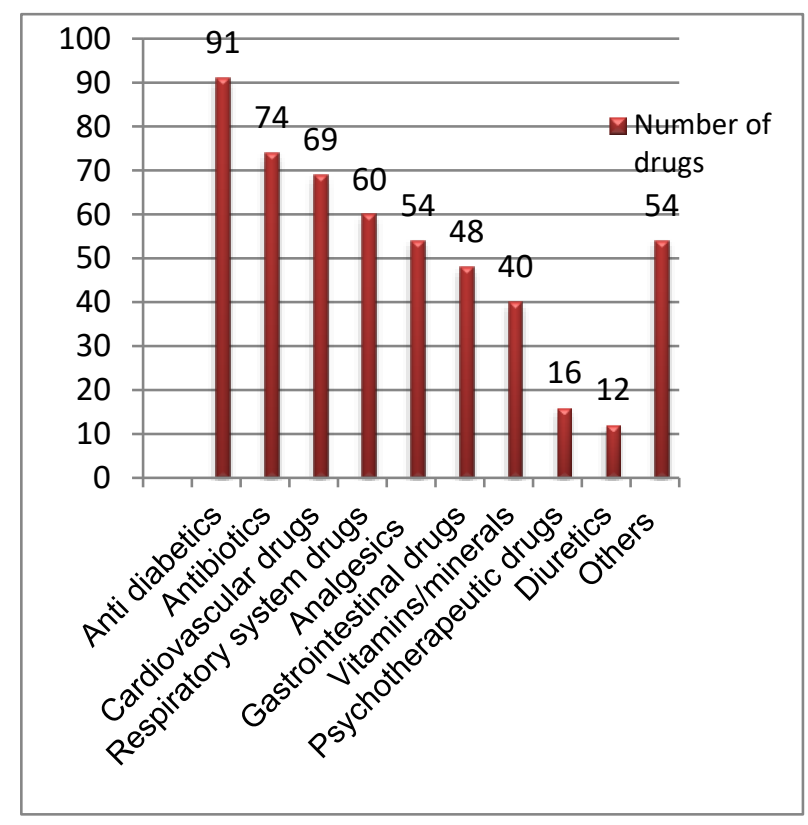

Figure 4: Most common drugs used.

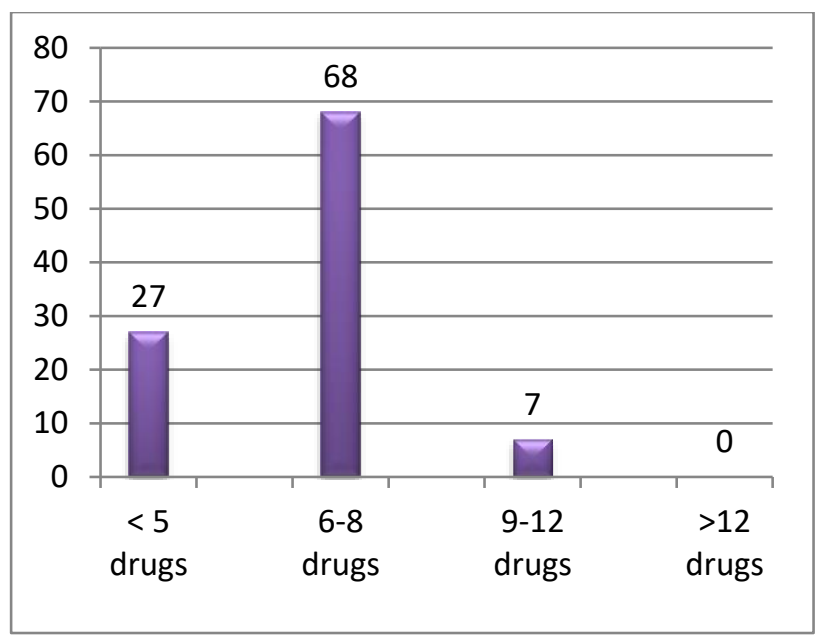

Figure 5: Number of drugs per prescription.

Table 1: Potentially inappropriate drugs prescribed based on Beer's criteria.

\begin{tabular}{|c|c|c|}
\hline Category & Name of drugs & $\begin{array}{l}\text { No. of } \\
\text { drugs }\end{array}$ \\
\hline \multirow{5}{*}{$\mathbf{A}$} & $\begin{array}{l}\text { Generally, to be avoided in } \\
\text { older adult }\end{array}$ & \\
\hline & Alprazolam & 4 \\
\hline & Diazepam & 3 \\
\hline & Chlorpheniramine & 2 \\
\hline & Diclofenac & 5 \\
\hline \multirow[t]{2}{*}{ B } & $\begin{array}{l}\text { Drugs that exceed maximum } \\
\text { recommended daily dose }\end{array}$ & \\
\hline & Bisacodyl & 4 \\
\hline $\mathbf{C}$ & $\begin{array}{l}\text { To be avoided in combination } \\
\text { with specific co morbidities }\end{array}$ & Nil \\
\hline
\end{tabular}

\section{DISCUSSION}

In this study most of the patient (67 out of 102) were in the age group 65-70 years with male population $(73 \%)$ dominance. The study conducted by Rozenfeld et al was reported by $85 \%$ of the sample, with a mean of 3.7 products per person (standard deviation=2.9). About half the sample used one to four medications and a third used five or more. The highest number of drugs used per patient was 24. More women than men used multiple medications. Men who reported five or more diseases were five times more likely to use multiple drugs than men with up to two (zero, one, or two) diseases (prevalence ratio 5.21, 95\% confidence interval $=2.48-10.90$ ). Women who reported five or more diseases were nearly four times more likely to use multiple drugs than women with up to two diseases (prevalence ratio 3.67, 95\% confidence interval $=2.24-$ 6.02). Of the active substances used by the sample, $10 \%$ were considered inappropriate. ${ }^{8}$

Most of the patient were admitted due to cardiovascular $(35.84 \%)$ and respiratory system $(14.15 \%)$ disorder. In a previous study among the elderly by Lohani et al, respiratory followed by cardiovascular disease were 
shown to be the predominant reasons for admission. ${ }^{9}$ Antidiabetics $(17.64 \%)$ followed by anti-microbials $(14.24 \%)$ were the most commonly prescribed medicines in this study. Ranitidine, aspirin, and diclofenac were reported as commonly utilized drugs by Shah et al. ${ }^{10}$ Whereas; ranitidine, multivitamins, amlodipine, ipratropium, and dinitro-salicylic acid were commonly observed drugs by Shankar. ${ }^{11}$

Our study revealed poly pharmacy in geriatric patients with an average number of drugs per prescription being 6.07. This deviates from the WHO standard of 1.6-1.8. In the present study according to BEER's criteria $3.47 \%$ of total drugs prescribed were inappropriate as compared to $4.1 \%$ in a study conducted by Harugeri et al in South India. ${ }^{12}$

\section{CONCLUSION}

In this study most of the patients had co morbid conditions which led to polypharmacy. A high number of potential prescription errors were found. The study has highlighted the need to pay attention to prescription writing and reduce the practice of inappropriate prescribing to aim at a healthy ageing in India

Funding: No funding sources

Conflict of interest: None declared

Ethical approval: The study was approved by the Institutional Ethics Committee

\section{REFERENCES}

1. Chanana HB, Talwar PP. Aging in India: Its Socioeconomic and health implications. Asia Pac Popul J. 1987;2:23-38.

2. Zaveri HG, Mansuri SM, Patel VJ. Use of potentially inappropriate medicine in elderly: A prospective study in medicine outpatient department of a tertiary care teaching hospital. Indian J Pharmacol. 2010;42:95-8.

3. Klotz U. Pharmacokinetics and drug metabolism in the elderly. Drug Metab Rev. 2009;41:67-76.

4. Corsonello A, Pedone C, Incalzi RA. Age-related pharmacokinetic and pharmacodynamic changes and related risk of adverse drug reactions. Curr Med Chem. 2010;17:571-84.
5. Gorzoni ML, Fabbri RM, Pires SL. Potentially inappropriate medications in elderly. Rev Assoc Med Bras. 2012;58:442-6.

6. Helldén A, Bergman U, Von Euler M, Hentschke M, Odar-Cederlöf I, Ohlén G. Adverse drug reactions and impaired renal function in elderly patients admitted to the emergency department: A retrospective study. Drugs Aging. 2009;26:595-606.

7. Lund BC, Steinman MA, Chrischilles EA, Kaboli PJ. Beers Criteria as a proxy for inappropriate prescribing of other medications among older adults. Ann Pharmacother. 2011;45:1363-70.

8. Rozenfeld S, Fonseca MJM, Acurcio FA. Drug utilization and polypharmacy among the elderly: a survey in Rio de Janeiro City, Brazil. Rev Panam Salud Publica. 2008;23(1):34-43.

9. Zhan C, Sangl J, Bierman AS, Miller MR, Friedman B, Wickizer SW et al.Potentially inappropriate medication use in the community-dwelling elderly findings from the 1996 medical expenditure panel survey. JAMA. 2001;286:2823-9.

10. Lohani SP, Thapa P, Aryal UR, Satyal KR, Polypharmacy and geriatric patients: patterns of prescribing in the Thribuvan University Teaching Hospital in Nepal. J Nepal Health Res Council. 2006;4:1-4.

11. Shah RB, Gajjar BM, Desai SV. Drug utilization pattern among geriatric patients assessed with the anatomical therapeutic chemical classification/defined daily dose system in a rural tertiary care teaching hospital. Int J Neur Pharmacol Neurol Dis. 2012;2:258-65.

12. Shankar PR, Upadhyay DK, Subish P, Bhandari RB, Das B. Drug utilization among older inpatients in a teaching hospital in Western Nepal. Singapore Med J. 2010;51:28-34.

13. Harugeri A, Joseph J, Parthasarathi G, Ramesh M, Guido S. Potentially inappropriate medication uses in elderly patients: A study of prevalence and predictors in two teaching hospitals. J Postgrad Med. 2010;56:186-91.

Cite this article as: Mohan PBN, Jayaram S. A prospective study on prescribing pattern of drugs in geriatric patients in the department of medicine in a tertiary care center. Int J Basic Clin Pharmacol 2021;10:293-6. 